\title{
Haesbaert, R. (2019). Regional-global. Dilemas de la región y de la regionalización en la geografía contemporánea.
}

Buenos Aires: CLACS0 y editorial FILO-UBA. Bogotá: UPN, 176 pp.

\author{
MARTÍN SEVAL
}

Facultad de Humanidades y Ciencias, Universidad Nacional del Litoral, Argentina mseval@fhuc.unl.edu.ar

La geografía regional tiene una larga historia en Argentina que comienza en la segunda mitad del siglo XIX y encuentra un punto de inflexión a fines del siglo XX. Esta se relaciona a un discurso regionalista clásico que, desde diferentes enfoques, fue consolidando una idea de región asociada a un área singular con elementos naturales (primero) y antrópicos (luego) en equilibrio, homogénea y uniforme, delimitable e individualizable que permite una división exhaustiva y mutuamente excluyente de subáreas. Entre sus referentes ${ }^{\mathrm{I}}$ pueden mencionarse inicialmente a naturalistas europeos como Víctor Martin de Moussy y geógrafos europeos como Pierre Denis, para luego consolidarse en propuestas vernáculas de referentes como Federico Daus, Mariano Zamorano, Elena Chiozza y Juan Alberto Roccatagliata, quienes lograron la difusión de la región como categoría analítica y categoría de acción política.

El discurso regionalista clásico tuvo una creciente influencia en la geografía vernácula desde sus comienzos, sin embargo, en la década del 80 del siglo XX la idea de región que instala es desacreditada y la región es abandonada como categoría analítica ${ }^{2}$. De esa manera, la geografía

1 En el artículo "150 años de geografía regional en Argentina: cambios y continuidades en las propuestas de regionalización del territorio nacional (1839 a 1988)" publicado en 2016 en la Revista Folia Historia del Nordeste, № 25, Alejandro Benedetti y Esteban Salizzi realizan un análisis detallado de las cuatro oleadas de regionalistas que difundieron e instalaron el discurso regionalista clásico en Argentina.

2 En el artículo "Geografías regionales en la Argentina. Imagen y valorización del territorio durante la primera mitad del siglo XX" publicado en 2002 en la Revista Scripta Nova, vol. $\mathrm{VI}(127)$, Silvina Quinteros plantea que desde la década de los 80 se produce "la pérdida de relevancia de la regionalidad como clave de escritura de las nuevas geografías argentinas". 
regional se ve desplazada de un debate académico que irá adoptando paulatinamente, de forma dicotómica, las categorías analíticas del debate territorial, como territorio, territorialidad y el binomio derivado de la territorialización, es decir, desterritorialización-reterritorialización.

La desacreditación y el abandono de la región como categoría analítica por parte de la geografía vernácula se da de forma concomitante a un momento en el que la región es resignificada por el mainstream internacional y observa continuidad como categoría de acción política en gran parte de América latina, incluso en Argentina ${ }^{3}$. Por un lado, una serie de aportes provenientes de la geografía económica, la geografía urbana, la geografía política europea comienzan a desandar un discurso nuevo-regionalista que incorpora nuevas formas de entender a la región. Por otro lado, las diferentes escalas del Estado comienzan a desplegar instrumentos de política pública para involucrarse en la construcción de regiones de forma conjunta con actores provenientes de la sociedad civil organizada, con el objetivo de fomentar regiones productivas y regiones urbanas a partir de nuevas formas de gobernanza público-privadas.

La reciente publicación del libro "Regional-Global. Dilemas de la región y de la regionalización en la geografía contemporánea” se inserta en este contexto y revive los debates regionales en Argentina y en gran parte de América Latina. Quien comience su lectura podrá apreciar en sus primeras páginas que el mismo es una reedición del libro editado en 2010 por Rogerio Haesbaert ${ }^{4}$, sin embargo, desde el ámbito académico la traducción del portugués al castellano no debería quedar limitada a una mera estrategia editorial. El libro forma parte de un grupo de aportes que resignifican la categoría región en el mundo de habla hispana, el cual en las últimas décadas le ha dado la espalda a la región como categoría analítica, desde diferentes disciplinas entre las que se encuentra la geografía, pese a que esta ha perdurado como categoría de acción política.

3 En el libro "La trilogía del erizo-zorro. Redes globales, trayectorias nacionales y dinámicas regionales desde la periferia" publicado en 2017 de forma conjunta entre EdicionesUNL y Anthropos, Víctor Ramiro Fernández abordar el rol y alcance que tuvo la región como categoría de acción política en un contexto caracterizado por el despliegue de redes globales políticas y económicas.

4 La primera edición en portugués es publicada en 2010 por la Editora Bertrand Brasil, Rio de Janeiro, con el título original "Regional-Global: dilemas da região e da regionalização na Geografia contemporânea". 
El gran aporte del libro se trata de la mirada de Rogerio Haesbaert en la que analiza los procesos de regionalización derivados de un contexto globalizador, homogeneizador, que pareciera no respetar límites, considerando las estrategias espaciales de reproducción y/o disputa entre los grupos hegemónicos y las estrategias contra-hegemónicas que los grupos subalternos despliegan en su cotidianeidad. Desde esta perspectiva, en términos generales, la estructura del libro nos ayudará a desandar el derrotero del debate regional desde la categoría región, analizando sus significados, planteando sus resignificaciones e incorporándola a un debate mayor que plantea su relación con otras grandes categorías que suelen ser objeto de interés de la geografía. De esta forma pueden entenderse los tres capítulos en los que se estructura el libro: el Capítulo I. Región y regionalización: la trayectoria del debate, el Capítulo 2. Por otra región: la región como artefacto y el Capítulo 3. La región en una "constelación" de conceptos: espacio, región y territorio.

En el primer capítulo, Rogerio Haesbaert desanda los derroteros de un largo debate en torno a la categoría región. Utiliza como disparador la polisemia del concepto a través de un recorrido por las siete acepciones de región del Oxford English Dictionary, para luego abordar la historia del concepto desde sus orígenes y analizar esta historia a partir de la metáfora de la vida y la muerte de la región. Esta metáfora hace referencia a las resignificaciones y las desacreditaciones, respectivamente, de la idea de región por parte del neopositivismo, el marxismo, el globalismo moderno, el posestructuralismo y las perspectivas neomodernas. En este recorrido platea la necesidad de revisitar la asociación de región con la idea parte/todo y la idea de poder que actualmente se encuentra asociada a la categoría territorio, porque, en palabras del autor, "toda regionalización se debe considerar siempre como un acto de poder: el poder de recortar, de clasificar e inclusive, muchas veces, también de nombrar" (Haesbaert, 2019:27)

En este recorrido teórico, en el que asocia región con regionalización, la cuestión central es ¿quién regionaliza? ¿para qué se construyen las regiones? ¿cómo se relaciona con los significados otorgados a la idea de región? En este sentido, el autor agrupa las diferentes posturas a partir de los contrapuntos de John Agnew entre "regiones en la mente" y "regiones de la mente" para diferenciar posiciones "realistas" y "constructivistas". A partir de estos contrapuntos propone denominar las resignificaciones analizadas como perspectivas de la región como hecho 
(concreto) y perspectivas de la región como artificio (teórico), para diferenciar aquellas perspectivas que buscan una evidencia "real" reconocida y/o producida desde el ámbito materialista o idealista, de aquellas perspectivas que buscan un instrumento, medio o constructo moldeado por el sujeto en un ámbito más estrictamente epistemológico.

En el segundo capítulo, Rogerio Haesbaert identifica otra región, la región como artefacto. Luego de haber agrupado las posturas en relación con su concepción de región como hecho y como artificio, el autor esboza un camino alternativo para identificar una tercera perspectiva que presenta a las regionalizaciones como instrumento para propuestas concretas de transformación. En pocas palabras, la región adopta la forma de un proyecto regional de ciertos actores que plantea una construcción regional específica que es la que efectivamente irá tomando forma en el espacio como procesos de regionalización concretos. A diferencia de la región como "artificio", la región como artefacto no se trata de un artificio moldeado para la comprensión de lo que es la región, identificando su esencia, sino para proyectar lo que ella debe(ría) ser e intervenir en la realidad. Un debe(ría) ser que habilita el debate sobre el espacio como un ámbito en disputa y recupera la región asociándola a la idea parte/todo y la idea de poder que actualmente se encuentra asociada a la categoría territorio.

La región como artefacto ingresa en la disputa entre lógicas de diferentes actores, una lógica zonal identificada inicialmente por las concepciones clásicas que convive con una lógica reticular típica de las redes desplegadas por el proceso de globalización. En esta disputa se produce la interpelación de las características básicas con las que suelen presentarse a las regiones. La especificidad que hace de la región algo singular se enfrenta a la ponderación de las diferencias, los principios de homogeneidad y cohesión demandan considerar los procesos de precarización, contención y exclusión, la cuestión de la continuidad espacial es tensionada por la posibilidad de entenderlas como parcelas relacionales diferencialmente articuladas y el carácter escalar intermedio que las presenta como mesoescalas es interpelado por las múltiples escalas de la que participan los actores involucrados en el proyecto regional y convocados para la construcción regional.

En el tercer capítulo, Rogerio Haesbaert retoma este debate planteando la incorporación de la región como categoría analítica como parte de lo una "constelación" de conceptos, denominación que retoma 
de la propuesta de Gilles Deleuze y Felix Guattari. En esta constelación de conceptos geográficos incorpora al espacio, a la región y al territorio desde la asociación explícita de espacio-territorio y territorio-región para indagar en las fronteras conceptuales sus tensiones y relaciones. La primera asociación plantea las particularidades del concepto espacio y de territorio, buscando superar la idea de espacio como noción y de territorio como concepto desde un sentido relacional que plantea esta frontera. Este hace hincapié en la forma de ejercer y concebir el poder desde una dimensión espacial que termina asociando al territorio más a la idea de territorialidad y territorialización desde procesos materiales y simbólicos. La segunda asociación plantea las particularidades del concepto territorio y región a partir de la frontera epistemológica entre territorialización y regionalización, ambas asociadas directa e indirectamente a la idea de poder.

En este punto es oportuno citar a Rogerio Haesbaert quien señala que, si bien la asociación directa entre espacio y poder se relaciona con los conceptos derivados del debate territorial, y pese que pueden identificarse diferentes perspectivas,

...la regionalización, al proponer identificar parcelas del espacio articuladas o dotadas de relativa coherencia, que sirvan como instrumento para nuestras investigaciones, revela, al mismo tiempo, articulaciones ligadas indisociablemente a la acción concreta de control, producción y significación del espacio por los sujetos sociales que las construyen, en el entrecruzamiento entre múltiples dimensiones (económica, política, cultural, entre otras) -aunque una de ellas, variable de acuerdo con el contexto geográfico e histórico, pueda imponerse y, de algún modo, "amalgamar" a las demás-. (Haesbaert, 20I9:137)

A modo de conclusión, Rogerio Haesbaert señala que la región y la regionalización no desaparecen frente a la desacreditación académica y a la aparente homogeneización del proceso de globalización, porque las diferencias y desigualdades permanecen y, sobre todo, porque son parte de una visión integrada que continúa viva en movimientos, identidades, representaciones y políticas. En este contexto, la categoría región continúa viva en un capitalismo global que indirectamente revitaliza los regionalismos e identidades regionales, el discurso regionalista de las cuestiones ambientales y el rol central de la región en los procesos de descentralización y desconcentración. Lo que subyace a esta continuidad son diferentes perspectivas de regionalización, la cual se nos 
presenta como instrumento de análisis, de la práctica, de intervención y como artefacto, una regionalización como proceso teórico y práctico.

En este punto se refuerza la idea de destacar que la reedición de este libro, en su versión traducida del portugués al castellano, no debería quedar limitada a una mera estrategia editorial sino a la necesidad de revivir el debate regional vernáculo y resignificar sus principales categorías de análisis frente a la simultánea continuidad de la región como categoría de acción política en Argentina y en gran parte de América latina. En este sentido, si bien el autor señala que optar por uno de los criterios de regionalización no significa estar abordando estudios menos "verdaderos" sino responder a preguntas, indagaciones y problemáticas específicas de diferentes proyectos de investigación; es oportuno destacar lo que subyace a la idea de región como artefacto si se pretende abordar quién, para qué y cómo se construyen las regiones. Este punto toma relevancia en la implicación de las diferentes escalas del Estado, a partir del despliegue de instrumentos de política pública de desarrollo regional, en la construcción de regiones de forma conjunta con actores provenientes de la sociedad civil organizada, tanto en el fomento de regiones productivas como de regiones urbanas a partir de nuevas formas de gobernanza público-privadas. Lo que supone la idea de región como artefacto, o como mera construcción regional a partir de un proyecto regional, nos permitirá considerar las acciones concretas que producen diferenciación en las estrategias de distintas articulaciones sociales en el espacio.

Los aportes teóricos de Rogerio Haesbaert nos permiten dar continuidad al debate regional sin reificar a la región como categoría analítica, planteando definiciones y conceptualizaciones que pretendan generalizarse a todos los casos. Se trata de una propuesta que nos interpela a indagar las concepciones de región que operan en la sociedad en general y en los actores públicos y privados que ponen en marcha procesos de regionalización a partir de una construcción regional en la que subyacen proyectos regionales específicos. En este sentido, el presente libro es parte de una larga trayectoria en torno a los debates regionales y los debates territoriales del autor, por lo que al ser de acceso libre se convierte en una buena oportunidad para comenzar a indagar la propuesta teórica de Rogerio Haesbaert y, sobre todo, para reconsiderar el lugar de los debates regionales en la geografía contemporánea. 